\title{
REVIEW
}

Cite this: DOI: 10.1039/x0xx00000x

Accepted 00th January 2014

DOI: $10.1039 / \times 0 \times x 00000 x$

www.rsc.org/

\section{Molecular containers in complex chemical systems}

\author{
Salvatore Zarra, † Daniel M. Wood, † Derrick A. Roberts† and Jonathan R. \\ Nitschke*
}

\begin{abstract}
Over the last decade molecular containers have been increasingly studied within the context of complex chemical systems. Herein we discuss selected examples from the literature concerning three aspects of this field: complex host-guest behaviour, adaptive transformations of molecular containers and reactivity modulation within them.
\end{abstract}

\section{Introduction}

Complex chemical behaviour is a defining feature of living organisms. Even the simplest living entities, e.g. prokaryotes, are complex systems comprised of many interlinked parts and pathways. ${ }^{1}$ Although scientists have long recognised complexity as a key feature of natural systems, it is only in the last 10 years that chemists have embraced systems chemistry, i.e. the study of the complex behaviour of mixtures of molecules. ${ }^{2}$ Complexity in chemistry is a difficult concept to define precisely, and has been described in different ways depending on the context of specific chemical systems and the viewpoint of the observer. ${ }^{3}$ In the present review we define a complex system as not just a complicated mixture of many chemical species, but a system in which the interactions between species give rise to one or more properties that cannot be ascribed to any one individual component, thus arising from the system as a whole.

In the last decade, species with well-defined inner void spaces able to accommodate guests, herein defined as molecular containers, ${ }^{4}$ have been increasingly studied within complex mixtures of molecules. Our understanding of molecular containers has evolved significantly since its infancy, some forty years ago, ${ }^{5}$ when the seminal works of Lehn, Cram and Pedersen, amongst others, were published. These early studies laid the foundations of supramolecular chemistry, ${ }^{6}$ which now includes different classes of container molecules that span a wide range of physicochemical properties and functions. ${ }^{7}$ In this review we aim to discuss the recent advances in this field by focusing on three different aspects of complexity: (i) complex host-guest binding behaviour of molecular containers; (ii) adaptive transformations of molecular containers that make up parts of complex systems; and (iii) using molecular containers for reactivity modulation in multistep reaction cascades.
In the first section of this review we discuss complex hostguest systems, focusing on those that show kinetic and thermodynamic social self-sorting. ${ }^{8}$ In early host-guest systems a single molecular container interacted with a single guest (or with multiple equivalents of the same guest). Since this time, studies of host-guest chemistry have expanded to encompass simultaneous interactions between different molecular containers and the same guest, ${ }^{9}$ different guests that interact simultaneously with the same host, ${ }^{10}$ and many different hosts that interact with many different guests. ${ }^{8,11}$

In the second section we highlight the development of chemical networks from which molecular containers emerge, focusing on the influences of different stimuli on the structures that are observed. Within such systems, the assembly and transformation of a given molecular container, occurring under thermodynamic control, is due to the selection of a specific structure amongst many possible alternatives in a dynamic library ${ }^{12}$ and can be influenced by several different factors.

The third section discusses how an advanced understanding of host-guest binding, self-sorting and dynamic self-assembly, as described in the first two sections, has led to the use of molecular containers in reactivity modulation, which represents a complex function of the molecular container platform. We define some of the unique roles that molecular containers can serve in reactivity modulation, and highlight key examples that illustrate the unprecedented spatial and temporal influences that encapsulation can have on the course and outcome of a chemical reaction.

This review is designed to present selected examples from the recent literature and to discuss each of the topics outlined above without being exhaustive. Other excellent reviews on molecular containers and their functions can be found in the literature $\mathrm{fc}^{73}$ and in the present themed issue. 


\section{Complex host-guest behaviour}

Complex mixtures of chemicals that undergo self-sorting, i.e. the high fidelity ${ }^{14}$ recognition between complementary chemical species, ${ }^{15}$ have been increasingly studied in the last decade as part of the new discipline of systems chemistry. ${ }^{2}$ In this section we will discuss guest binding within molecular containers in complex chemical systems. We adopt the definitions for the various types of self-sorting proposed by $\mathrm{Wu}$ and Isaacs. $^{16}$ Systems can self-sort either kinetically or thermodynamically and the self-sorting can be either narcissistic (i.e. species with high affinity for themselves) or social (i.e. species with high affinity for others).

Seminal work on social self-sorting of a multicomponent host-guest system including molecular containers was reported by Isaacs and co-workers in $2004 .^{8}$ Their system consisted of 12 components ( 6 hosts and 6 guests), including the molecular containers cucurbit[6]uril ( $\mathrm{CB}[6]), \mathrm{CB}[8]$ and $\beta$-cyclodextrin. Upon combining all 12 components, and after equilibration, six host-guest complexes formed with high fidelity thanks to the high stability constant of each complementary host-guest pair. The equilibrated system was analysed by ${ }^{1} \mathrm{H}$ NMR spectroscopy, relying on the well-separated sets of resonances displayed by each component of the complex system and the slow exchange dynamics of each host-guest complex on the NMR timescale. These NMR features, which enable straightforward analysis of a multicomponent system, are common to the other examples examined later in this section. The outcome of a self-sorting experiment is dependent on the conditions under which it was performed. Isaacs and coworkers investigated the influences of temperature, $\mathrm{pH}$, concentration and stoichiometry on their twelve-component system through a combination of simulations and experiments. ${ }^{8}$ For example, following a heating/cooling cycle the system was observed to undergo an irreversible transformation involving new interactions between different host-guest pairs, which emerged as a property of the mixture as a whole.

In 2006 the Isaacs group reported the investigation of a four-component system, i.e. two molecular containers $(\mathrm{CB}[6]$ and $\mathrm{CB}[7])$ and two guests, one of which featured two binding sites (Fig. 1, two-faced guest depicted in green and orange). The guests were selected following an iterative process that sought to achieve a high fidelity kinetic self-sorting state before equilibration to the high fidelity thermodynamic state (Fig. 1). ${ }^{17}$ This selection process involved the preparation and NMR analysis of four-component mixtures without prior knowledge of their binding kinetics and thermodynamics. This was coupled with the use of a computational step to rationalise the outcomes of each experiment. This iterative procedure guided the preparation of the next mixture so as to obtain the desired high fidelity self-sorted system. After investigating approximately 20 pairs of guests, Isaacs and co-workers developed a system wherein the two-faced guest would first bind $\mathrm{CB}[6]$ with its narrower end under kinetic control (Fig.1, on the left). Then, upon equilibration, it would bind to $\mathrm{CB}[7]$ with its wider end, thus reaching the thermodynamic state (Fig.
1, on the right). At the same time the other guest would first bind to $\mathrm{CB}[7]$ and then to $\mathrm{CB}[6]$. Therefore, a systems chemistry approach, based on the preparation and observation of complex chemical mixtures followed by the rationalisation of the outcome, can be used to discover multicomponent systems for guest binding.

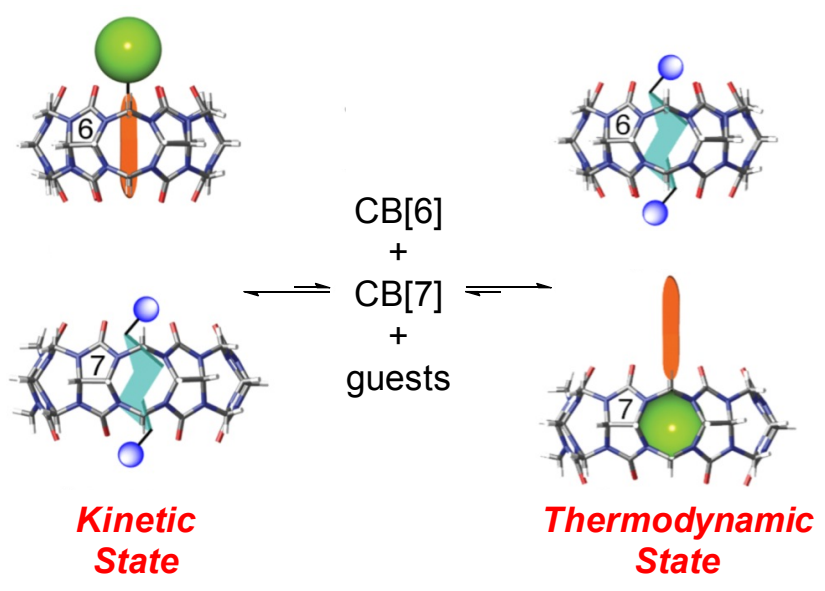

Fig. 1 Kinetic and thermodynamic states of the four-component system studied by Isaacs and co-workers. The two-faced guest, featuring two binding sites, is depicted in green and orange. Figure adapted from ref. 17.

The complementary reductionist approach, involving the detailed study of the kinetics and thermodynamics of a series of host-guest complexes, has enabled our group to design a system wherein a single metal-organic capsule (Fig. 2, 1) binds three different guests in successive steps, thus displaying first two kinetic self-sorted states and then the final thermodynamic self-sorted state (Fig. 2). ${ }^{18}$ The guests employed in this experiment (acetone, chloroform and 1,3,5-trioxane) were selected amongst a range of 19 possible guest molecules, for which kinetic and thermodynamic data of binding had been determined. Only with this quantitative information could the multicomponent system be 'programmed' to behave as shown in Fig. 2. Since the binding studies were conducted in water, the main driving force for the binding within capsule $\mathbf{1}$ is guest hydrophobicity; thus, more hydrophobic guests bind more strongly. The rate of encapsulation, in contrast, depends upon the size and shape of the guest. ${ }^{18}$ When a pH-sensitive guest (pyridine) was employed in the presence of two other guests (acetone and tetrahydrofuran, THF) the same capsule was shown to cycle between a thermodynamic self-sorted state at $\mathrm{pH}=7$, in which pyridine was bound within capsule $\mathbf{1}$, and a different equilibrium state at $\mathrm{pH}=4$, corresponding to mostly THF bound (Fig. 3). ${ }^{18}$ Moreover, the system was designed to go from one thermodynamic state to the other through an intermediate kinetic state, wherein mostly acetone was bound within the capsule (Fig. 3). The Isaacs group has also used $\mathrm{pH}-$ sensitive guests to prepare a four-component system capable of intermolecular guest swapping between two different molecular containers following the change in $\mathrm{pH}$ of the solution. ${ }^{19}$ 

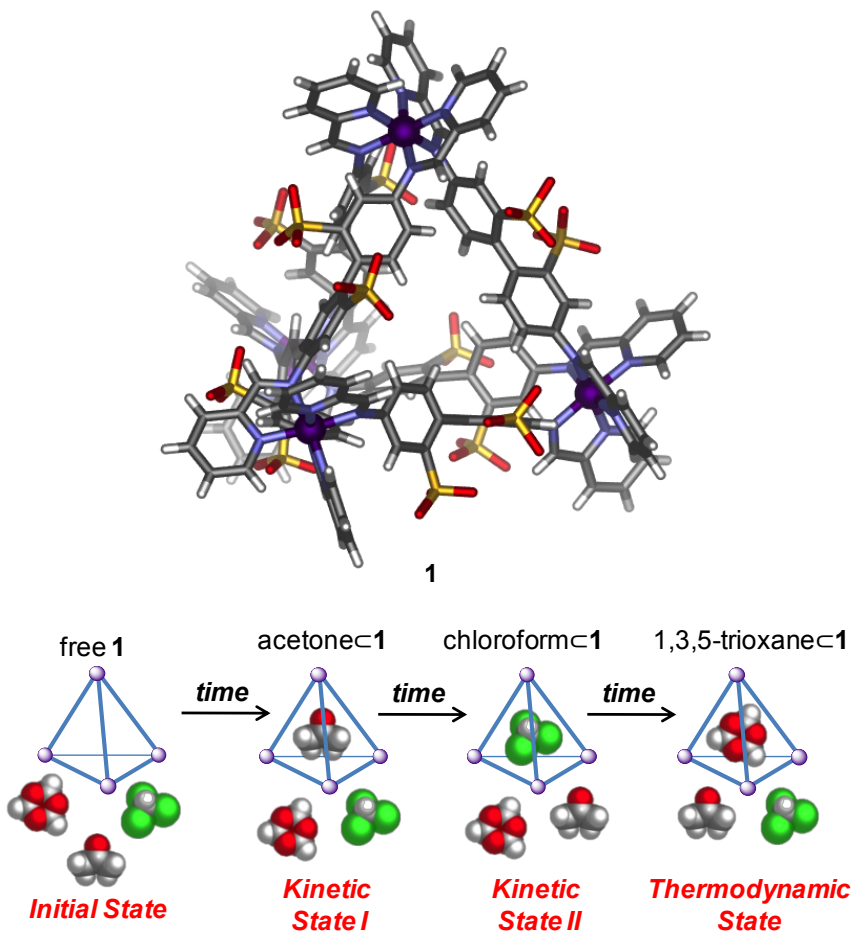

Fig. 2 Top: X-ray crystal structure of $\mathbf{1}$, which is a water-soluble metal-organic capsule assembled by our group. ${ }^{20}$ Bottom: two kinetic states and the thermodynamic state of the four-component host-guest system described by our group. Figure adapted from ref. 18.



Fig. $3 \mathrm{pH}$-controlled cycle between two thermodynamic states by going through a kinetic state for the four-component host-guest system designed by our group. Figure adapted from ref. 18.

Rebek and co-workers have reported a seven-component mixture comprising a dimeric capsule and six $n$-alkane guests $\left(\mathrm{C}_{9}, \mathrm{C}_{10}, \mathrm{C}_{11}, \mathrm{C}_{12}, \mathrm{C}_{13}\right.$ and $\left.\mathrm{C}_{14}\right)$, which displayed sequencespecific kinetics for guest encapsulation. ${ }^{10 \mathrm{~b}}$ The system was monitored by NMR spectroscopy and was observed to probe two kinetic states, corresponding to the encapsulation of $\mathrm{C}_{9}$ and then $\mathrm{C}_{10}$, before the binding of $\mathrm{C}_{11}$ in the thermodynamic state. Host-guest complexes for the other alkanes were observed solely as minor products during the experiment. Therefore, the behaviour of this seven-component system is very similar to that of a system comprising only the dimeric capsule, $\mathrm{C}_{9}, \mathrm{C}_{10}$ and $\mathrm{C}_{11}$. The encapsulation rates for those alkanes were measured to be in the order $\mathrm{C}_{9}>\mathrm{C}_{10}>\mathrm{C}_{11}$, whereas the binding affinities followed the reverse order, $\mathrm{C}_{11}>\mathrm{C}_{10}>\mathrm{C}_{9}$.
The self-sorting of two different deep-cavity cavitands (Fig. 4 , depicted in green and blue), in the presence of various alkanes, was investigated by Gan and Gibb. ${ }^{21}$ These cavitands can form either homo- or hetero-dimers, both of which bind alkanes (Fig. 4, on the right). One of the cavitands can also bind alkane guests in its monomeric form (Fig. 4, $\mathrm{R}=\mathrm{Me}$ ). The ratios between the various host-guest complexes for the mixture of cavitands and one alkane guest (n-pentane to $n$ hexadecane) were measured after equilibration by NMR spectroscopy. Following the analysis of the data it was deduced that the degree of self-sorting between the various host-guest complexes was dependent on the size of the guest.
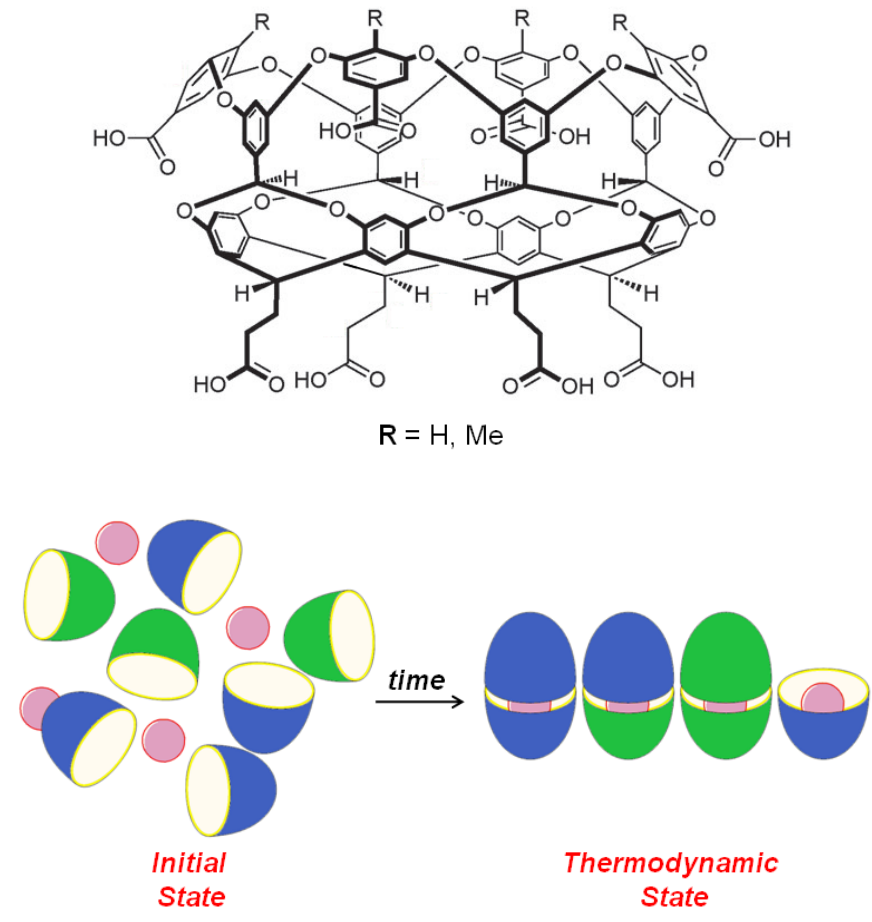

Fig. 4 Top: resorcinarene-based deep-cavity cavitands employed by Gan and Gibb. ${ }^{21}$ Bottom: a three-component system can generate four different hostguest complexes at the thermodynamic equilibrium, as described by Gan and Gibb. The ratios between them depend on the guest identity, as they differ from the expected statistical values. Cavitands are depicted in green $(R=H)$ and blue $(R=M e)$; alkane guest is represented as a red sphere. Figures adapted from ref. 21.

Another study involving an eight-component (4 molecular containers and 4 guests, shown in Fig. 5) thermodynamic selfsorted system was reported by Isaacs and co-workers. ${ }^{22}$ Its stepwise preparation in eight steps following different pathways was performed both experimentally and in silico. The number of thermodynamic states accessible with eight components is $2^{8}$, i.e. 256 . These states can either be self-sorted or not, based on the definition that a non-self-sorted state is characterised by one or more components or complexes with mole fractions between 0.1 and 0.9 . The number of pathways to generate the final eight-component thermodynamic self-sorted state is the factorial of 8 , i.e. 40320. 


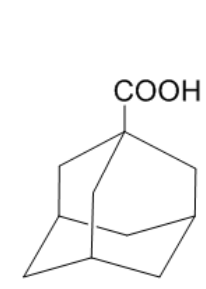

3

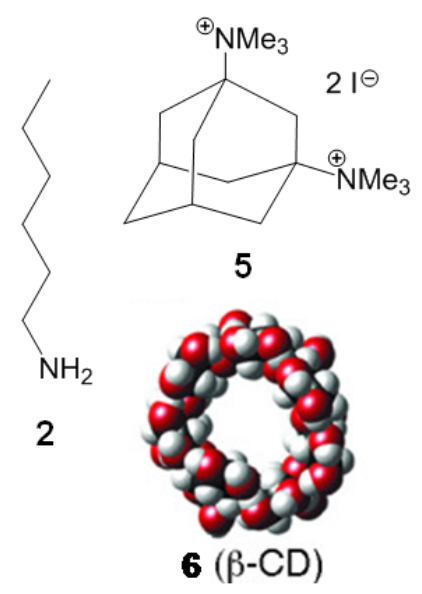



$7(\mathrm{CB}[6])$



8 (CB[7])

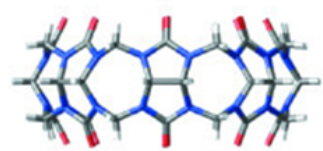

$9(\mathrm{CB}[8])$
Fig. 5 The eight-component host-guest system studied by Isaacs and co-workers. Figure adapted from ref. 22.

The self-sorted nature of the final state does not imply selfsorting of the intermediate states. Therefore, completely selfsorted pathways are possible as are non-self-sorted intermediate states. The number of self-sorted states and pathways was shown to depend on the sequence of addition of the components, their concentrations and the binding affinities of the host-guest complexes. For example, the stepwise addition of $2,9,4,6,5,8,3$ and then 7 resulted in a self-sorted pathway.

\section{Adaptive Transformations of Self-Assembled Molecular Containers}

Molecular containers can be obtained through the self-assembly of small, complimentarily-functionalised building blocks into three-dimensional assemblies. $^{7 \mathrm{c}, 13 \mathrm{~b}, 13 \mathrm{c}}$ Such systems require the container species to be the thermodynamic product so that the reversibly-formed interactions between building blocks can rearrange to yield the molecular container upon equilibration through an error-checking pathway. ${ }^{13 b, 23}$ Recently there has been interest in designing container systems in which the thermodynamic product changes depending on the reaction conditions. This can give rise to molecular containers with dramatically different architectures, allowing species to be generated having different sizes and that can accommodate different guests.

Shionoya et al. reported one of the earliest examples of a 3D metal-organic assembly capable of undergoing a structural transformation - an example which demonstrated that it was possible to alternate between $2 \mathrm{D}$ and $3 \mathrm{D}$ assemblies by controlling the relative concentrations of the components in the system. ${ }^{24}$ They devised a simple two-component system based on a $C_{3}$-symmetric tris(benzimidazolyl) ligand $\mathbf{1 0}$ (Fig. 6) and $\mathrm{Ag}^{\mathrm{I}}$ ions. Combining equimolar quantities of $\mathbf{1 0}$ and silver triflate (AgOTf) in a mixture of $\mathrm{CDCl}_{3}$ and $\mathrm{CD}_{3} \mathrm{OD}$, afforded a single species, tetrahedral capsule $\mathrm{Ag}_{4} \mathbf{1 0}_{4}$ (11). Upon the addition of a further 0.5 equivalents of AgOTf, 11 was observed to transform into the sandwich complex $\mathrm{Ag}_{3} \mathbf{1 0}_{2}$ (12). The concentration dependence of this system was probed by NMR titration experiments, which indicated the presence of both 11 and 12 in solution when the concentration of AgOTf was in the range of 1-1.5 equivalents per 10. Compounds $\mathbf{1 1}$ and 12 thus exist in a dynamic equilibrium, the position of which is controlled by the ratio between the two components. The favoured complex is the one that offers the greatest enthalpic stabilisation by maximising the number of coordinative $\mathrm{N} \rightarrow \mathrm{Ag}^{\mathrm{I}}$ interactions in solution.



Fig. 6 Schematic representation of tris-benzimidazolyl ligand (10) and conversion between tetrahedron 11 and sandwich complex $\mathbf{1 2}$ with varying amount of AgOTf. Figure adapted from ref. 24.

Shionoya et al. further demonstrated the utility of this form of rearrangement behaviour by using it to control host-guest interactions in a system. ${ }^{25}$ A larger disk-shaped tris(monodentate) ligand 13 with alternating 3-pyridyl and $p$ tolyl groups attached to a central benzene ring was shown to coordinate $\mathrm{Ag}^{\mathrm{I}}$ in $\mathrm{CD}_{3} \mathrm{NO}_{2}$ to form either the $\mathrm{Ag}_{4} \mathbf{1 3}_{4}$ tetrahedral capsule 14 or the larger $\operatorname{Ag}_{6} \mathbf{1 3}_{4}$ adamantane-shaped cage 15 (Fig. 7). Capsule 14 possesses an internal cavity suitable for encapsulating neutral organic molecules such as adamantane, whereas $\mathbf{1 5}$ is more porous and does not form host-guest species. The dynamic nature of this system made it possible to control the encapsulation/release of the adamantane guest by varying the concentration of AgOTf added. Adding additional AgOTf to a solution containing (adamantane) $\subset \mathbf{1 4}$ resulted in the capsule transforming into $\mathbf{1 5}$, releasing the adamantane guest. This process reversed upon addition of $[2,2,2]$-cryptand 
to complex the additional $\mathrm{Ag}^{\mathrm{I}}$ ions, reforming (adamantane) $\subset \mathbf{1 4}$.

Yoshizawa et al. recently reported a similar system that utilises molecular containers formed from anthracene ligands and $\mathrm{Hg}^{\mathrm{II}}$ ions to encapsulate fullerenes. ${ }^{26}$ A common theme in this kind of stoichiometrically controlled complex formation is the use of labile, weakly coordinated metal ions that can bind ligands in different coordination geometries.

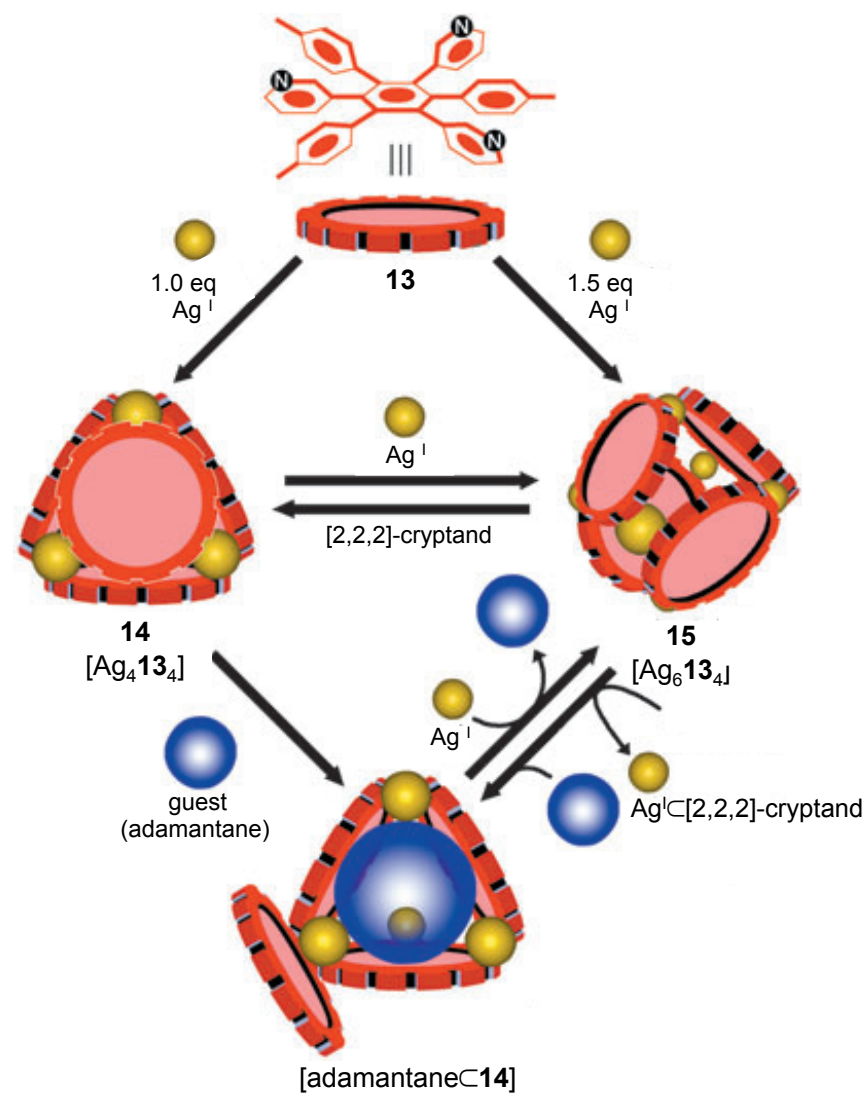

Fig. 7 Schematic representation of the interconversion between $\mathbf{1 4}$ and $\mathbf{1 5}$ and controlled encapsulation and release of adamantane from 14. Figure adapted from ref. 25 .

An example from our group employed the encapsulation of anions to drive the formation of different container species. ${ }^{27}$ The combination of $p$-toluidine, 6,6'-diformyl-3,3'-bipyridine and cobalt(II) triflimide, $\mathrm{Co}\left(\mathrm{NTf}_{2}\right)_{2}$, in acetonitrile did not yield a single chemical species, but an intractable library of different complexes in solution. However, by replacing $\mathrm{Co}\left(\mathrm{NTf}_{2}\right)_{2}$ with cobalt(II) triflate, $\mathrm{Co}(\mathrm{OTf})_{2}$, it was possible to obtain a $\mathrm{Co}_{4} \mathrm{~L}_{6}$ tetrahedral assembly $\left(\mathrm{OTf}^{-} \subset \mathbf{1 6}\right)$ accommodating a single encapsulated $\mathrm{OTf}^{-}$anion within its cavity.

A similar effect was initially observed when $\mathrm{KPF}_{6}$ was added to the original $\mathrm{Co}\left(\mathrm{NTf}_{2}\right)_{2}$ solution, with the $\mathrm{PF}_{6}{ }^{-}$anion templating the formation of $\mathrm{PF}_{6}{ }^{-} \subset \mathbf{1 6}$. However, after heating this solution for several days ${ }^{1} \mathrm{H}$ NMR analysis of the solution showed that the signals for $\mathrm{PF}_{6}{ }^{-} \subset \mathbf{1 6}$ had been replaced with a new set of resonances which were found to correspond to a novel $\mathrm{Co}_{10} \mathrm{~L}_{15}$ pentagonal prism $\mathbf{1 7} \cdot \mathrm{PF}_{6}$ (Fig. 8). The X-ray crystal structure showed that $\mathbf{1 7} \cdot \mathrm{PF}_{6}$ contained different binding pockets: five around the periphery that housed $\mathrm{PF}_{6}^{-}$and a central cavity that had encapsulated an adventitious chloride guest. Adding $\mathrm{LiClO}_{4}$ instead of $\mathrm{KPF}_{6}$ rapidly yielded only 17. $\mathrm{ClO}_{4}$ without forming the tetrahedral species as a kinetic intermediate, indicating that the size and shape of the anion present in the system affect not just the assembly obtained but also the rate of formation.

The behaviour of this system in the presence of different anions formed the basis of a more complex chemical network whereby combinations of anions promote the formation of the two different architectures. Adding $\mathrm{KPF}_{6}$ to a solution of OTf $\subset 16$ initially yielded a mixture of $\mathrm{PF}_{6}{ }^{-} \subset 16$ and $\mathrm{OTf} \subset \mathbf{} \subset \mathbf{1 6}$ that, over time, formed a mixture of isomers of $\mathbf{1 7}$, with each isomer containing a different combination of $\mathrm{OTf}^{-}$and $\mathrm{PF}_{6}^{-}$. By contrast, the addition of $\mathrm{LiClO}_{4}$ to the system only ever yields 17. $\mathrm{ClO}_{4}$, regardless of the other anions present, indicating that this is the thermodynamic product of the system. The behaviour of this system is defined by the stabilising effect of binding anions within the cationic assemblies. The observation that different species are obtained in the presence of different anions can be attributed to the differences in size and shape between $\mathrm{PF}_{6}^{-}$, OTf and $\mathrm{ClO}_{4}^{-}$. Moreover, additional favourable contribution to the formation of $\mathbf{1 7}$ is likely due to extensive $\pi$ $\pi$ stacking between electron-rich $p$-toluidine residues and electron-poor metal-bound pyridine groups.

A recent system from Shionoya et al. exploited anion coordination at the corners of a metal-organic capsule to influence the assembly obtained. ${ }^{28}$ They described a $C_{4^{-}}$ symmetric tetrakis(2,2'-bipyridine)porphyrinatozinc(II) ligand 18 that, when combined with $\mathrm{Zn}(\mathrm{OTf})_{2}$ in a $\mathrm{CDCl}_{3} / \mathrm{CD}_{3} \mathrm{OD} / \mathrm{D}_{2} \mathrm{O} \quad(10: 10: 1)$ solvent mixture, yields hexameric cage complex 19 with formula $\left[\mathrm{Zn}_{11} \mathbf{1 8}_{6}\left(\mathrm{H}_{2} \mathrm{O}\right)_{18}\right](\mathrm{OTf})_{22}$ that could be characterised by ${ }^{1} \mathrm{H}$ NMR and ESI-MS (Fig. 9). The X-ray crystal structure of 19 shows that the $\mathrm{Zn}^{\mathrm{II}}$ metal ions exist in three different ligand environments: two $\mathrm{Zn}{ }^{\mathrm{II}}$ centres were bound by three bipyridine (bpy) groups, and the remaining nine centres took the general form cis- $\mathrm{Zn}(\mathrm{bpy})_{2}\left(\mathrm{H}_{2} \mathrm{O}\right)_{2}$. The presence of water as a co-solvent was found to be essential to the formation of 19; when the reaction was carried out in $\mathrm{CD}_{3} \mathrm{Cl} / \mathrm{CD}_{3} \mathrm{OD}$ (1:1) no discrete assembly was observed to form. Additional studies showed that the binding strength of different solvents and anions as ligands to $\mathrm{Zn}^{\mathrm{II}}$ further impacts the structure of the assembly formed. ${ }^{29}$ By observing the formation of mononuclear $\mathrm{Zn}^{\mathrm{II}} 2,2^{\prime}$-bipyridine complexes in the presence of different anions and solvents, it became possible to predict the $\mathrm{Zn}^{\mathrm{II}}$ environments within assemblies incorporating $\mathbf{1 8}$ under those conditions. The authors found that, in the presence of the more strongly coordinating tosylate anion $\left(\mathrm{OTs}^{-}\right)$, the formation of (bipy) ${ }_{2} \mathrm{Zn}^{\mathrm{II}}(\mathrm{OTs})_{2}$ centres was preferred and led to the formation of a new tetrameric $\left[\mathrm{Zn}_{8} \mathbf{1 8}_{4}(\mathrm{OTs})_{16}\right]$ capsule (20) that binds $\mathrm{C}_{60}$. Weakly binding anions, such as $\mathrm{NO}_{3}^{-}$, favoured the formation of (bpy) ${ }_{3} \mathrm{Zn}^{\mathrm{II}}$ centres and yielded no single product, whereas slightly more coordinating anions $\left(\right.$ or $\left.\mathrm{H}_{2} \mathrm{O}\right)$ allowed the 
formation of the mixture of different (bpy) $\mathrm{Zn}^{\mathrm{II}}$ and $(\mathrm{bpy})_{2} \mathrm{Zn}^{\mathrm{II}} \quad$ centres required to form the previously observed hexamer 19.

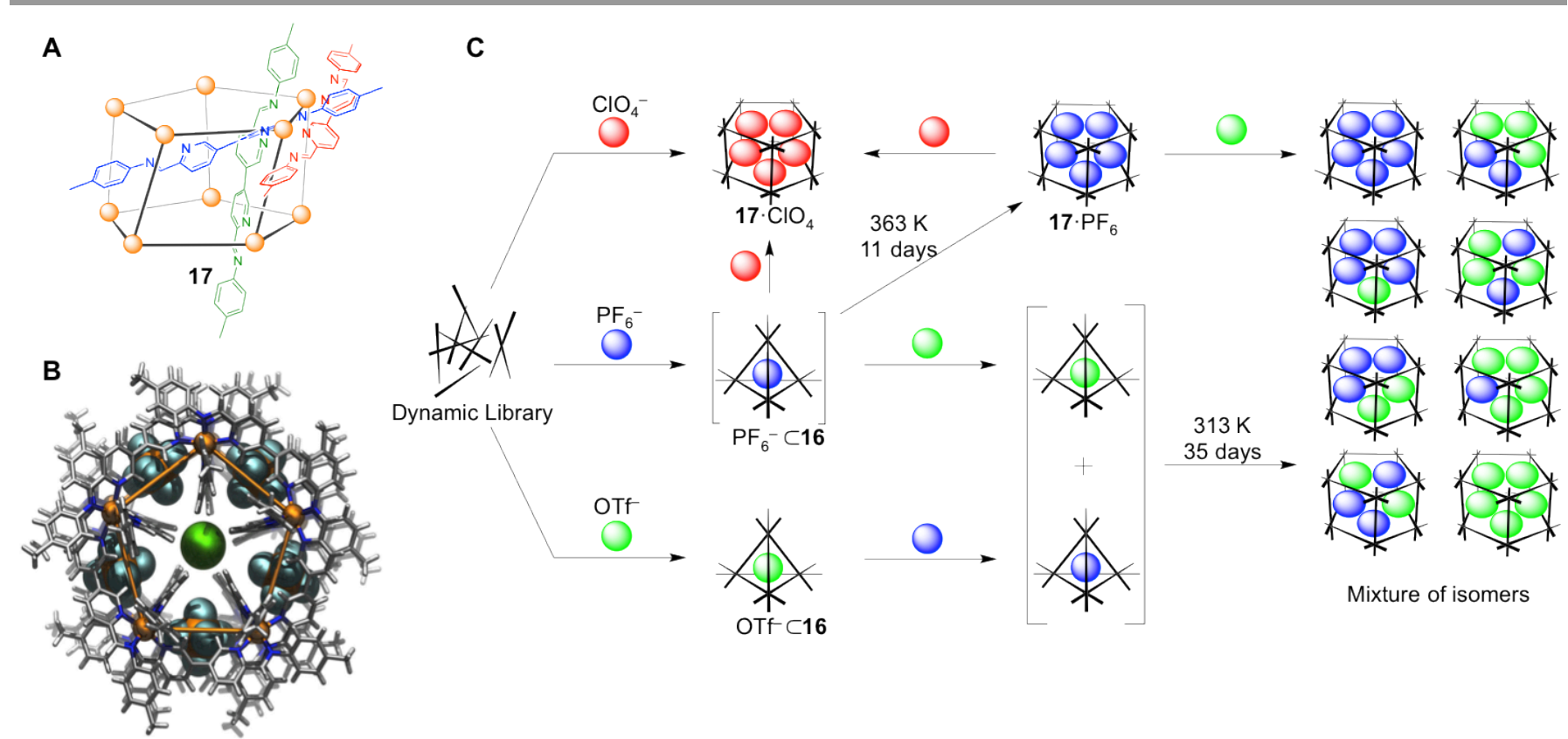

Fig. 8 (A) Schematic representation of pentagonal prism 17. (B) View down the centre of the crystal structure of $17 \cdot \mathrm{PF}_{6}$. (C) Chemical network showing the effects of the sequential addition of different anions on the assembly obtained from the system (red spheres indicate $\mathrm{ClO}_{4}{ }^{-}$, blue $\mathrm{PF}_{6}{ }^{-}$and green $\mathrm{OTf}^{-}$). Figure adapted from ref. 27.

Stefankiewicz and Sanders have developed a dynamic combinatorial library of water-soluble tri- (21) and di-thiol (22) compounds that form covalent container species around polyamine templates. ${ }^{30}$ When exposed to air under basic conditions the thiol groups of $\mathbf{2 1}$ and $\mathbf{2 2}$ oxidise and form a library of different disulfide-based homo-macrocycles that were observed by LC-MS. Upon addition of spermine, the LC trace for the mixture showed a decrease in signals associated with homo-assemblies and the emergence of new signals that corresponded to several container species formed from disulfide linked ensembles of 21 and 22 (Fig. 10). Each molecular container comprised 2 units of $\mathbf{2 1}$ and between 5 and 9 units of 22. The ratio of different molecular containers did not change at different concentrations of spermine template, thus suggesting that all the amplified containers possess similar spermine association constants. Different polyamine templates affect the library of container species formed, with the shorter 1,4-butanediamine forming only the 9-mer and 10-mer containers. The different responses of the library in the presence of different polyamines could be used as the basis of a pattern-recognition approach to identifying these different substrates.

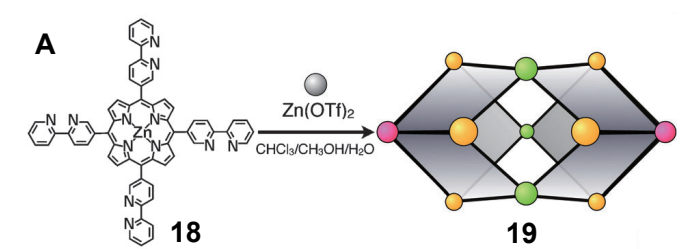

B


Fig. 9 (A) Scheme for the formation of hexameric container 19. (B) Description of the effect of different anions on the $\mathrm{Zn}^{\prime \prime}$ coordination environments obtained. 
Coloured circles indicate the different $\mathrm{Zn}$ " arrangements. Figure adapted from refs. 28 and 29.

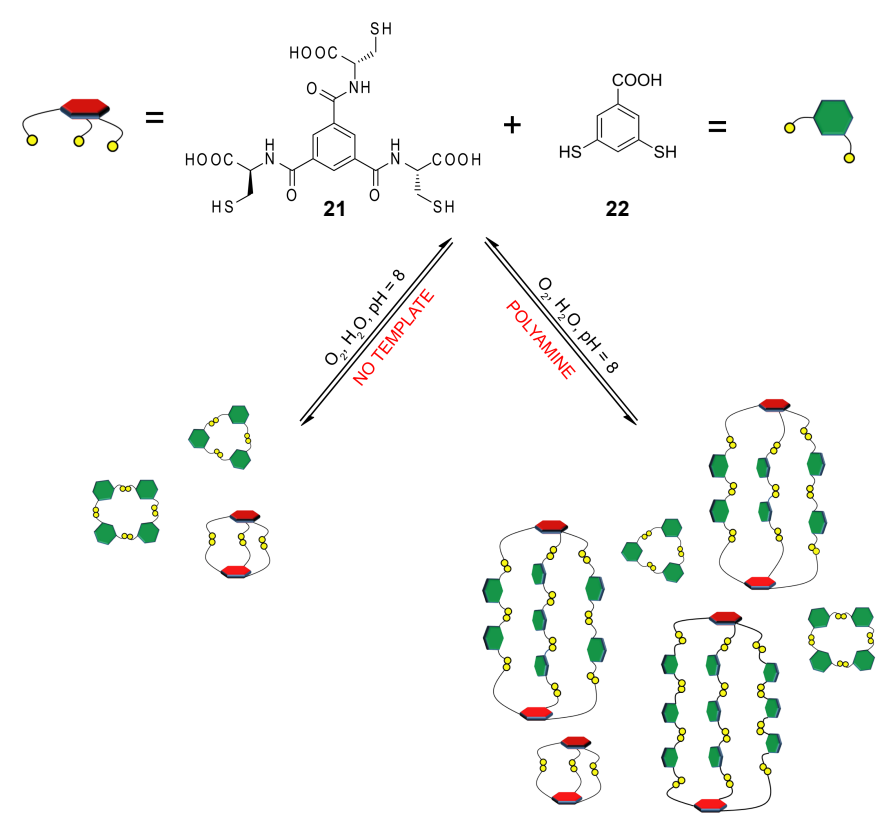

Fig. 10 Schematic representation of the dynamic combinatorial library of multicomponent cages based on trithiol $\mathbf{2 1}$ and dithiol 22. Figure adapted from ref. 30 .

The emergence of topologically complex species based on molecular containers in a chemical system started with early work from Fujita and Yoshizawa utilising stacking interactions between triazine-based containers and pyrene guests to form interpenetrating structures. ${ }^{7 \mathrm{~d}}$ In a more recent study, Kuroda and Sekiya have described a system of mechanically interlocked container dimers whose formation can be controlled by the choice of anion bound within the container. ${ }^{31}$ Monomeric container $\mathbf{2 3}$ was prepared from a bis(monodentate) pyridine-based ligand and $\mathrm{Pd}(\mathrm{OTf})_{2}$ in DMF. 23 was found to be persistent in the presence of $\mathrm{OTf}^{-}$and $\mathrm{PF}_{6}{ }^{-}$in $\mathrm{DMSO}$, but upon addition of $\mathrm{NO}_{3}^{-}$underwent dimerisation to form quadruply interlocked dimer $\mathbf{2 4}$ with three $\mathrm{NO}_{3}{ }^{-}$anions bound within its cavities (Fig. 11). A previous study of $\mathbf{2 3}$ showed that the anions 2-naphalenesulfonate $\left(\mathrm{ONs}^{-}\right)$and tosylate $\left(\mathrm{OTs}^{-}\right)$ could bind inside the container through the formation of $\mathrm{Pd}^{2+\ldots-}$ $\mathrm{O}_{3} \mathrm{SR}$ interactions. ${ }^{32}$ However, heating a solution of $\mathbf{2 4}$ in the presence of $\mathrm{NaONs}$ yielded only a small amount of $\left(\mathrm{ONs}^{-}\right)_{2} \subset \mathbf{2 3}$ and the retention of $\mathbf{2 4}$ with a mixture of $\mathrm{NO}_{3}{ }^{-}$and ${ }^{-} \mathrm{ONs}$ bound in its internal cavities. By contrast, the addition of NaOTs afforded $\left(\mathrm{OTs}^{-}\right)_{2} \subset \mathbf{2 3}$ as a white precipitate in greater yield ( $68 \%$ of 24 converted to monomer). This process was aided by the low solubility of the OTs ${ }^{-}$salt of $\mathbf{2 3}$ and provided a convenient method for controlling the formation and degradation of the topological isomers.

The formation of interlocking dimeric container species has also been investigated at length by the Clever Group ${ }^{33}$ and has been the subject of other recent reviews. ${ }^{13 b, 34}$



Fig. 11 Scheme for the anion-induced degradation of interlocked dimer $\mathbf{2 4}$ to monomeric container (OTs ${ }_{2}{ }_{2} \subset \mathbf{2 3}$. Figure adapted from ref. 31 .

\section{Molecular containers in multistep reaction cascades}

A guest, when trapped inside the central cavity of a molecular container, behaves similarly to a substrate bound within a biochemical structure, e.g. an enzyme pocket or chaperone protein. ${ }^{35}$ For over four decades ${ }^{36}$ these similarities have inspired chemists to study molecular containers as well-defined nanospaces for controlling chemical reactions, often with the goal of mimicking enzymatic catalysis. ${ }^{37}$

When substrates become entrapped within a molecular container, they become isolated from the bulk reaction medium, stripped of their solvent shell and their motions may become restricted due to steric constraints within the host's cavity. ${ }^{38}$ This spatial confinement can stabilise reactive species and geometrically pre-organise substrates so as to promote a chemical reaction, thus leading to increased reaction rates and improved selectivity for certain reaction products, ${ }^{35}$ especially those not normally favoured under bulk conditions. ${ }^{39}$

Broadly speaking, synthetic nanoreactors can modulate a chemical reaction either by (i) directly altering the free energy of species (substrates and/or intermediates) along the reaction coordinate (on-pathway regulation); or (ii) by reversibly channelling reactive species away from the main reaction pathway through encapsulation (off-pathway regulation), i.e. serving as a supramolecular protecting group (Fig. 12). Onpathway regulators can be further divided into molecular containers that act as protective vehicles for (typically transition metal) catalysts, ${ }^{39 \mathrm{~d}, 40}$ and containers that have inherent catalytic activity, ${ }^{37 b, 38 a, 41}$ with both belonging to the broader class of synthetic nanoreactors. ${ }^{42}$ 



c



Fig. 12 Molecular containers can modulate chemical reactions through offpathway and on-pathway mechanisms. A generic bimolecular reaction is shown, in which reactants $\boldsymbol{a}$ and $\boldsymbol{b}$ react via a transitory intermediate $\boldsymbol{c}$ to give the product $\boldsymbol{d}$. (A) Off-pathway regulation: the container reversibly encapsulates reactive species, thereby channelling them away from the main reaction pathway to effect down-regulation. Adding a competitive guest can shift the host-guest equilibria, thus altering the bulk concentration of reactive species. (B) On-pathway regulation, whereby the molecular container brings the substrates into close proximity through encapsulation. (C) On-pathway regulation, whereby the container specifically encapsulates an intermediate, $\boldsymbol{c}$, to catalyse its transformation into $\boldsymbol{d}$. (D) On-pathway regulation, whereby a catalyst encapsulated within the molecular container effects the key transformations, but the container still directly participates in the main reaction pathway through more general cavity effects.

Employing molecular containers as synthetic nanoreactors in conventional synthetic organic reaction systems has been researched and reviewed previously, ${ }^{7 \mathrm{~b}, 38 \mathrm{~b}, 43 \mathrm{a}}$ and new molecular containers continue to be developed as highly efficient "molecular flasks". ${ }^{43 \mathrm{~b}-\mathrm{m}}$ In recent years this field of research has moved increasingly towards controlling complex reaction cascades, with a particular focus on reactions that operate under biologically compatible conditions. ${ }^{44}$ Reaction cascades can improve the efficiency of a multistep synthesis by obviating intermediate purification steps, reducing waste, and coupling multiple equilibria towards a single target product. $^{38 \mathrm{~b}, 44 \mathrm{~b}}$ Consequently, multistep reaction cascades are of great interest to the synthetic chemistry community.

A design criterion for new multicatalytic systems is ensuring compatibility between reaction components during the overall reaction sequence. ${ }^{44}$ This criterion will become increasingly challenging to meet as more complicated reaction systems are designed, and could potentially impose severe limitations on the practical scope of relay multicatalysis. Molecular containers offer a promising approach to improving compatibility in multicatalytic systems due to their ability to compartmentalise, and thus segregate, incompatible reaction components. $^{45}$ Employing molecular containers in these systems can also benefit from reaction enhancements due to the aforementioned cavity effects. ${ }^{38 \mathrm{~b}, 43 \mathrm{a}}$

In the following discussion we have sought to identify examples from the recent literature that advance the evolution of the molecular container as a platform for controlling complex multistep chemical reactions.

\section{A. Off-pathway supramolecular regulation in catalysis}

In the context of reactivity modulation, molecular containers provide an enclosed cavity inside which a chemical reaction can occur. While research and reviews in this area focus primarily on this role, ${ }^{7 b, 38 b, 42,43 a}$ we highlight that hosting a chemical reaction is not a prerequisite for reactivity modulation: molecular containers can also indirectly regulate a reaction by channelling reactive species away from the main reaction sequence by shunting them off-pathway.

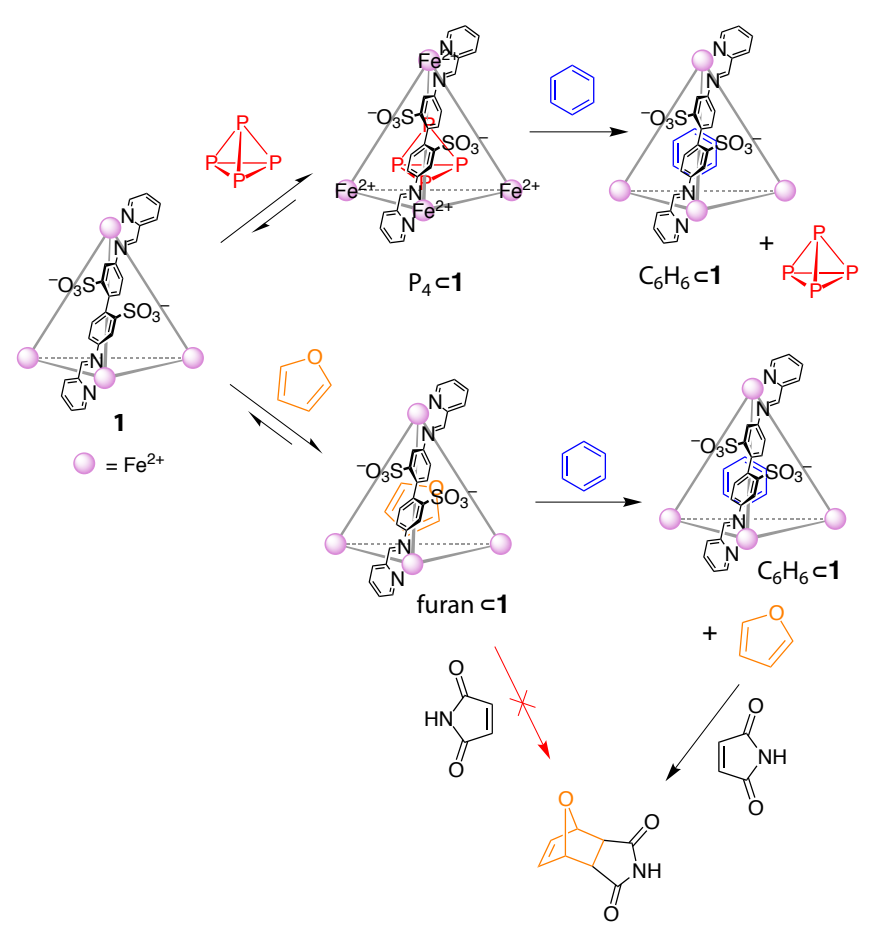

Fig. 13 Cage 1 is an off-pathway reaction regulator-it is able to reversibly sequester reactive species through encapsulation, thus preventing them from reacting until they are released from the molecular container, e.g. by a competitive guest (benzene in both pictured examples). Top: sequestration of highly reactive white phosphorus $\left(\mathrm{P}_{4}\right)$ by 1 . Bottom: encapsulation of furan within 1 enables supramolecular control over its Diels-Alder reaction with maleimide.

For instance, cage 1, reported by our group, ${ }^{20}$ encapsulates highly reactive white phosphorus (Fig. 13), protecting it from reacting with $\mathrm{O}_{2}$ until it is liberated by adding a competitive guest (e.g. benzene). ${ }^{46}$ More recently, this same cage has been used as a "whole-molecule protecting group" to control the rate of the Diels-Alder reaction between furan and maleimide by selectively encapsulating furan (Fig. 13). ${ }^{47}$ The host-guest 
equilibria between furan and $\mathbf{1}$ reduces the bulk concentration of furan, slowing the Diels-Alder reaction 25-fold compared to a benzene-initiated control experiment, in which benzene competitively displaces furan from host $\mathbf{1}$.

The reversible host-guest interactions that molecular containers support also offer a means of incorporating mechanical actuation into off-pathway chemical regulators. ${ }^{48}$ For example, Stoddart and Zink have developed mesoporous silica nanoparticles functionalised with CB-based pseudorotaxane nanovalves as a platform for the stimulusinduced delivery of small molecules loaded within a nanoparticle vector. ${ }^{49}$ Similarly, Isaacs and Rotello have developed diaminohexane-functionalised gold nanoparticles that bind complementary cucurbit[7]uril ( $\mathrm{CB}[7])$, making it possible to render the particles cytotoxic only when a competitive guest (1-adamantylamine) is supplied. ${ }^{50}$ In each of these systems the molecular container functions only as an offpathway signal transducer and binds none of the active reaction components (i.e. cytotoxic small molecule payloads, or inherently cytotoxic nanoparticles). Remarkably, each of these systems operates faithfully in cellular environments, thus demonstrating that the abiological nature of synthetic molecular containers can indeed provide a bio-orthogonal means of signal transduction in vivo.

Within the paradigm of molecular containers in bioorthogonal reaction systems, Isaacs and Ghosh have reported an example whereby a $\mathrm{CB}$ [7] molecular container mediates the activity of an enzyme by competing for a common Janus-type (two-faced) inhibitor molecule (Fig. 14, [i]) ${ }^{51}$ They prepared a library of rod-like inhibitor molecules featuring enzymebinding and $\mathrm{CB}$ [7]-binding epitopes on either end of their structures, which enables them to reversibly shuttle between the enzyme and the molecular container. Adding $\mathrm{CB}$ [7] to inhibited bovine carbonic anhydrase (BCA) results in the formation of a ternary enzyme-inhibitor-CB[7] complex (BCA-[i]·CB[7]), which then dissociates to give the active enzyme and the binary $\mathrm{CB}[7]$-inhibitor complex $(\mathrm{CB}[7] \cdot[\mathbf{i}])$. Enzyme activity could be subsequently switched off by displacing the inhibitor molecule with a preferential guest for $\mathrm{CB}[7]$, e.g. $N^{1}$-(adamantan-1yl)ethane-1,2-diamine (25).

The system reported by Ghosh and Isaacs is quite specific to enzymes with deep and sterically constrained binding sites. Indeed, $\mathrm{CB}$ [7] was unable to displace the inhibitor from aceytylcholinesterase (AChE), which has a much more shallow and less sterically hindered binding site than BCA. Furthermore, BCA appeared to be somewhat sensitive to the accumulation of $\mathrm{CB}$ [7] during continued on/off cycling of the enzyme. Nonetheless, this non-allosteric approach to biological reactivity modulation demonstrates that off-pathway regulation can be employed under biological conditions, and could be used to complement on-pathway molecular container regulators in more complicated reaction systems.

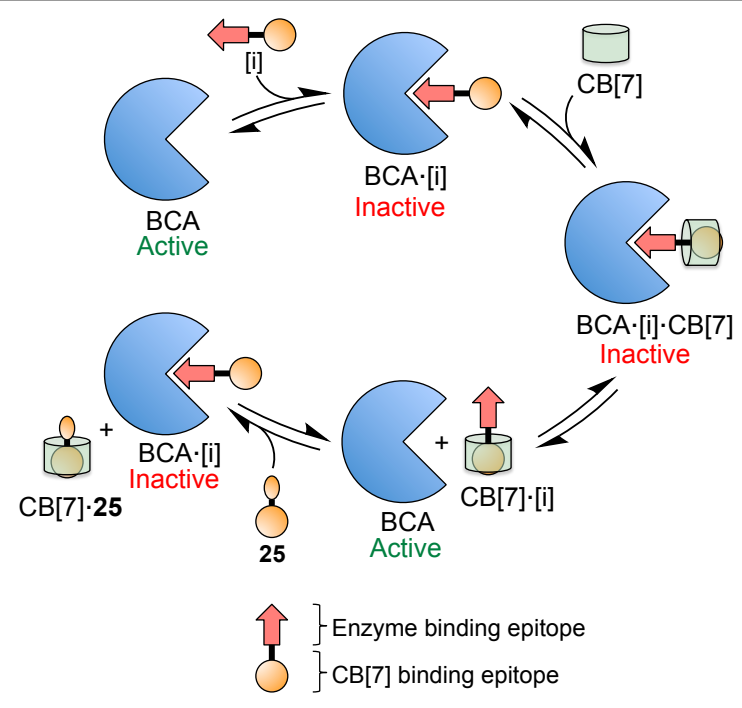

Fig. 14 Schematic mechanism summarising the control of bovine carbonic anhydrase (BCA) activity using a Janus-type inhibitor molecule, [i], and $\mathrm{CB}[7]$. Figure adapted from ref. 51 .

\section{B. Enzymatic tandem multicatalysis: coupling on-pathway regulators with enzymatic catalysis}

Tandem multicalysis has developed rapidly in recent years and a number of successful reaction cascades have been reported. ${ }^{44,52}$ Recent reviews on tandem multicatalysis identify the ongoing challenge of ensuring compatibility between the reaction components throughout the whole multicatalytic sequence. ${ }^{48,49}$ Molecular containers are well poised to help address the issue of compatibility in multicatalysis, as they are able to impose spatial segregation between incompatible reaction components, thus preventing unwanted cross-talk between the elementary steps. Additionally, molecular containers can stabilise reactive catalysts, thus improving their lifetimes, ${ }^{40,53}$ render hydrophobic catalysts water-soluble upon encapsulation, ${ }^{7 \mathrm{a}}$ and augment the performance of encapsulated catalysts through cavity effects. ${ }^{7 b, 38 b, 43 a}$

Coupling transition metal catalysis with enzymatic transformations is particularly challenging due to unwanted catalyst-protein interactions and solubility mismatching between the aqueous environment and hydrophobic catalyst. Raymond and co-workers have recently reported two remarkable tandem multicatalytic systems that combine a cagebound transition metal catalyst with enzyme-catalysed reactions under in vitro biological conditions. Both systems employed water-soluble $\mathrm{Ga}_{4} \mathrm{~L}_{6}$ (L = N,N'-bis(2,3-dihydroxybenzoyl)-1,5diamino-naphthalene) tetrahedral cage 26. ${ }^{41,54}$ Cage 26 was able to co-encapsulate a transition metal catalyst and a substrate molecule, which both prevents the metal catalyst from interfering with the enzyme while providing an enclosed space for the reaction to occur. Interestingly, these features make cage 26 a hybrid molecular container that executes concomitant onpathway (catalysis) and off-pathway (compartmentalisation) regulation.

In the first system studied, the authors devised a one-pot tandem reaction sequence whereby an allenic ester or amide 
was added to a water-DMSO solution containing an esterase or a lipase and the host-guest complex $\mathrm{Me}_{3} \mathrm{PAu}^{+} \subset \mathbf{2 6}$ (Fig. 15). In isolation, the esterases and lipases were proficient at cleaving the ester or amide functionality, respectively, of the allenic ester or amide. The $\mathrm{Au}^{\mathrm{I}}$ complex, on the other hand, catalysed the hydroalkoxylation of allenes, and displayed an eight-fold rate enhancement when encapsulated within cage $26^{54}$ When operating in tandem, enzymatic ester/amide hydrolysis initially unmasks the alcohol/amine functionality to afford the allenic alcohol. This intermediate subsequently undergoes $\mathrm{Me}_{3} \mathrm{PAu}^{+} \subset$ 26-catalysed intramolecular hydroxyalkylation at the allene group to afford the substituted tetrahydrofuran (Fig. 15). Importantly, neither the enzyme nor $\mathrm{Me}_{3} \mathrm{PAu}^{+} \subset \mathbf{2 6}$ could, in isolation, produce the tetrahydrofuran producthence, it arises as a product of the system rather than its individual components.



B

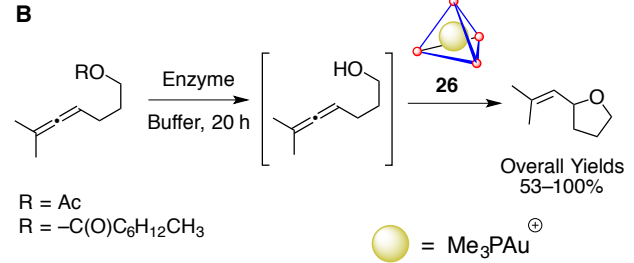

Fig. 15 (A) $\mathrm{Ga}_{4} \mathrm{~L}_{6}$ tetrahedral cage (26) can encapsulate transition metal complexes and substrate molecules, thereby making it an effective on-pathway regulator molecular container. (B) $\mathrm{Me}_{3} \mathrm{PAu}^{+} \subset 26$ can facilitate the hydroalkoxylation of allenic alcohols in water, and displays an 8-fold rate enhancement compared to the free gold complex. Overall yields are included for a range of esterases (rabbit liver, hog liver and horse liver) and $M$. miehei lipase. Figure adapted from ref. 54 .

Raymond and co-workers reported a second even more remarkable three-component multicatalytic system involving two dehydrogenase enzymes. ${ }^{55}$ As shown in Fig. 16, $\left(\mathrm{Me}_{3} \mathrm{P}\right) \mathrm{CpRu}(\mathrm{NCMe})_{2} \subset \mathbf{2 6}$ catalyses the isomerisation of $1-$ propenol to the corresponding aldehyde, which is in turn converted to 1-propanol by alcohol dehydrogenase (ADH) in $61 \%$ overall yield after six hours at $37^{\circ} \mathrm{C}$. The $\mathrm{ADH}$ step requires the input of nicotinamide adenine dinucleotide phosphate (NADPH) cofactor as a fuel. To avoid using a stoichiometric amount of NADPH, the authors coupled the $\mathrm{ADH}$ cycle to the oxidation of sodium formate by formate dehydrogenase (FDH) such that NADPH could be regenerated in situ. This process is reminiscent of a very simple organism, whereby the system is provided with "food" (in the form of sodium formate), and transfers its energy to down-stream synthetic operations via a small-molecule energy shuttle (NADPH). Once again, neither the enzyme couple nor the encapsulated ruthenium catalyst alone could carry out both reactions in the sequence.

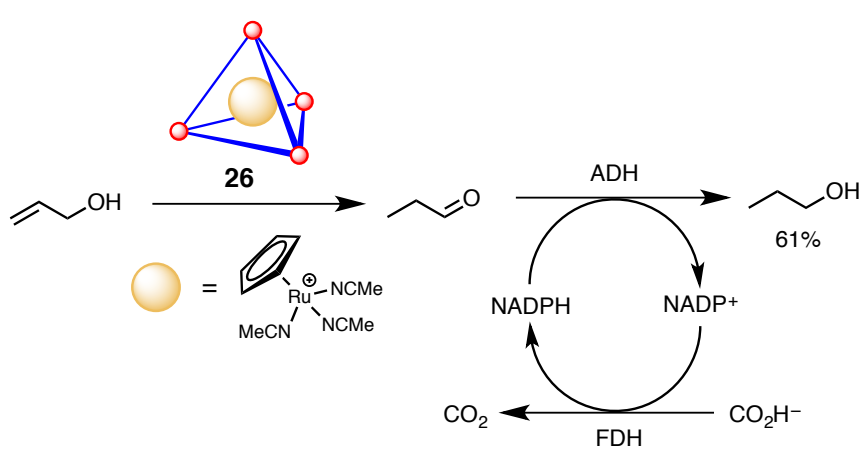

Fig. 16 Ru"-mediated olefin isomerisation of allyl alcohol to give propanal followed by reduction to propanol via ADH. Figure adapted from ref. 55 .

\section{C. In situ self-sorting and relay multicatalysis: a self-organising chemical assembly line}

Several authors note that self-assembled molecular containers are attractive as they are often easier to synthesise than their allcovalent counterparts and their designs are inherently modular, enabling high-throughput screening and tuning of their properties to suit specific experimental needs. ${ }^{9,38 b, 42,55}$ The selfassembly of a molecular container does, however, imply a certain degree of kinetic lability, as dynamic error-checking between the constituent subcomponents must occur in order to obtain the thermodynamically-stable complex. This feature renders self-assembled molecular containers potentially unstable under some reaction conditions (e.g. extremes of $\mathrm{pH}$, high temperature or in the presence of strong nucleophiles or electrophiles), and can undermine their utility as reactivity modulators. Consequently, self-assembled molecular container regulators are typically added to reaction systems as the stable, pre-formed complexes to avoid cross-talk between the reaction system and the container's own self-assembly processes. 


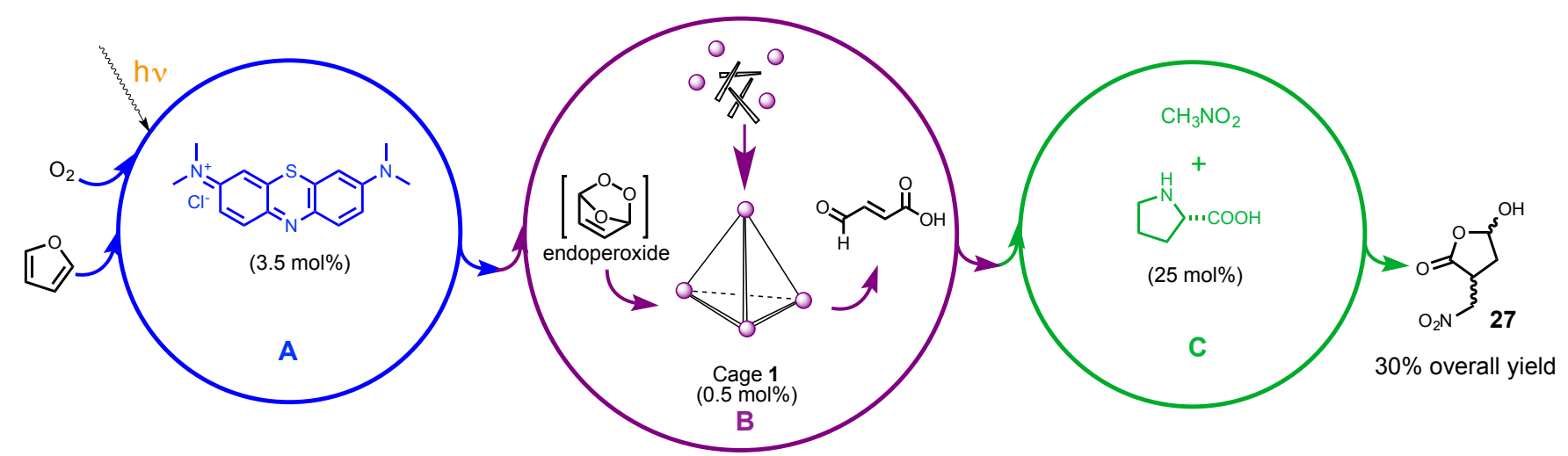

Fig. 17 Relay multicatalytic system (water, pH 4.0 at room temperature) in which three linked chemical pathways emerge from the self-organisation of a complex "molecular assembly line" in a single reaction flask. Figure adapted from ref. 56.

Recently, our group reported a relay $^{52}$ multicatalytic reaction system that features an additional level of system complexity by having the molecular container self-assemble in situ in the presence of all other reaction components, and then proceed to participate in a catalytic cycle. ${ }^{56}$ In this system, furan was fed into three coupled reaction cycles (Fig. 17), starting with singlet oxygen (photogenerated by methylene blue) addition to afford an endoperoxide intermediate (Fig. 17A), which is then converted to fumaraldehydic acid in the presence of cage 1 as a catalyst (Fig. 17B), and finally the L-proline-catalyzed 1,4-addition of nitromethane to fumaraldehydic acid to give the final product 27 in $30 \%$ overall yield (Fig. 17C). The self-assembled multicatalytic assembly line exploits the synthetic ease that self-assembly affords: in situ self-sorting and highly chemospecific self-assembly of molecular container 1 occurs in the presence of other reagents. Despite many opportunities for cross-talk between the reaction cycles and self-assembly of $\mathbf{1}$, the thermodynamic preferences of the system dictate faithful self-organisation into a functioning chemical assembly line. Thus, $\mathbf{1}$ not only participates in a complex chemical reaction sequence, but is also itself a complex chemical system.

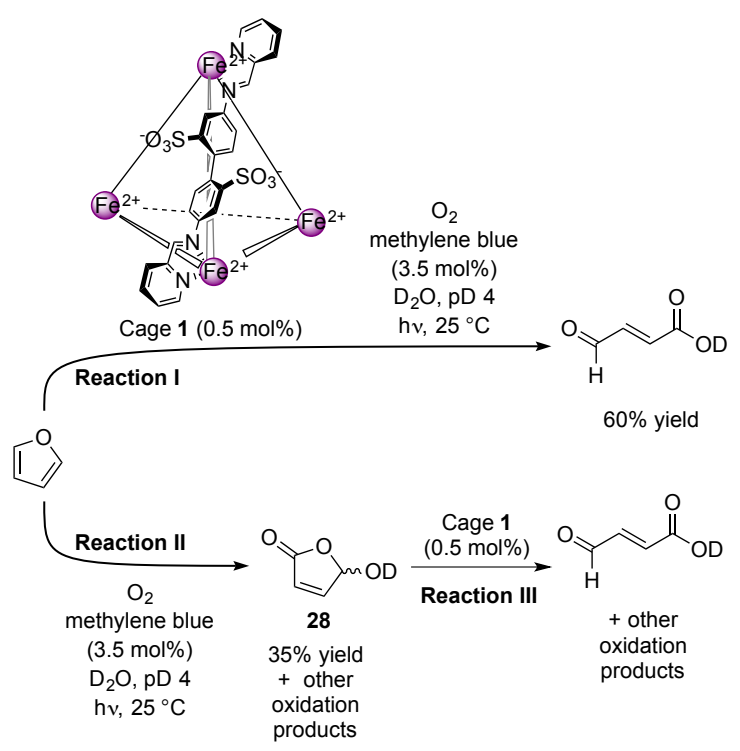

Fig. 18 Reaction of furan with singlet oxygen in the presence and absence of cage 1 affords different reaction products, suggesting some degree of pathway dependence for the overall reaction. Figure adapted from ref. 56.

In the multicatalytic sequences discussed in Section $3 \mathrm{~B}^{55}$ each elementary reaction step proceeded as anticipated, with each catalyst performing a known transformation to afford a product typical of that catalyst. The net product thus arises as the linear sum of the elementary catalytic operations. By contrast, the net reaction product from the multicatalytic system shown in Fig. 17 afforded an unprecedented overall product: the reaction of singlet oxygen with furan in the absence of the cage afforded hydroxybutenolide $\mathbf{2 8}$, whereas the presence of cage 1 gave selectively fumaraldehydic acid without any production of $\mathbf{2 8}$ (Fig. 18). Cage $\mathbf{1}$ was hypothesised to act upon a high-energy intermediate from singlet oxygen addition, such as an endoperoxide, thereby affording fumaraldehydic acid with high selectively (Fig. 17). Similar behaviour has been reported to emerge from existing cases of conventional (noncage-mediated) multicatalytic systems, and captures a defining feature of systems chemistry, whereby complex synergistic interactions within the system as a whole produce chemical 
behaviour that goes beyond the linear sum of its individual components. $^{2}$

\section{Conclusions}

The goal of this review has been to highlight the development of chemical systems that employ molecular containers as the agents of chemical complexity, whereby functional behaviour emerges from a network of coupled interactions occurring between the system's components. The collective understanding of molecular containers and their diverse physicochemical properties has matured dramatically over the past four decades. Supramolecular chemists, having developed a thorough understanding of the host-guest exchange dynamics of structures ranging from highly stable covalent architectures to labile dynamic systems, now have at their disposal a rich toolbox from which to build complex chemical systems regulated by synthetic molecular containers.

This review has focussed on reactivity modulation as a state-of-the-art application of molecular containers. Through a combination of off-pathway and on-pathway mechanisms discussed herein, and including the well-established cavity effects that encapsulation can produce, it is becoming increasingly possible to build complex one-pot reaction cascades in which molecular containers provide spatio-temporal control beyond what can currently be achieved in bulk media. These recent advances hint at the beginnings of an alternative to the rigorous multistep processes employed in conventional chemical synthesis.

Alongside the continued development of new molecular containers that better regulate chemical reactivity, we anticipate that future developments in this area will come from incorporating the dynamic reconfiguration discussed in Section 2 as a form of allosteric regulation, providing a means of upand down-regulating reaction pathways. Natural systems make extensive use of allostery, but it is only starting to feature more prominently in supramolecular chemistry now, with seminal papers focusing on non-container systems. ${ }^{37 a, 57}$

While allosteric regulation in molecular containers is still in its infancy, current work on the field is laying foundations for the future of more complex chemical regulators. ${ }^{33,58}$

The continued pursuit of an understanding of the fundamental properties of molecular containers will ultimately lead to the development of applications, ranging from reactivity modulation and catalysis in industrial contexts to drug vectors and chemical sensing devices, which promise economic value and industrial significance.

\section{Author information}

Department of Chemistry, University of Cambridge, Lensfield Road, Cambridge, CB2 1EW, UK. E-mail:jirn34@,cam.ac.uk

\section{Author contributions}

$\dagger$ These authors contributed equally.

\section{Acknowledgements}

The UK Engineering and Physical Sciences Research Council (SZ, JRN), The European Research Council (DMW) and the Gates Cambridge Trust (DAR) are acknowledged for financial support. The authors thank C. S. Wood and W. J. Ramsay for proofreading the manuscript.

\section{Notes and references}

1. Y. Diekmann and J. B. Pereira-Leal, Biochem. J., 2013, 449, 319.

2. R. F. Ludlow and S. Otto, Chem. Soc. Rev., 2008, 37, 101.

3. (a) G. M. Whitesides and R. F. Ismagilov, Science, 1999, 284, 89; (b) A. C. Balazs and I. R. Epstein, Science, 2009, 325, 1632; (c) B. C. Gibb, Nat. Chem., 2011, 3, 3.

4. In the present review the term 'molecular container' refers to any compound with an internal void suitable to be occupied by other chemical species. This broad definition covers a plethora of different species, including metal-organic cages, cavitands, hemicarcerands, covalent capsules, cucurbiturils and cyclodextrins.

5. (a) C. J. Pedersen, J. Am. Chem. Soc., 1967, 89, 2495; (b) B. Dietrich, J.-M. Lehn and J. P. Sauvage, J. Chem. Soc. Chem. Commun., 1973, 15; (c) D. J. Cram, Science, 1983, 219, 1177; (d) D. J. Cram, M. E. Tanner and C. B. Knobler, J. Am. Chem. Soc., 1991, 113, 7717; (e) R. W. Saalfrank, A. Stark, K. Peters and H. G. Vonschnering, Angew. Chem. Int. Ed., 1988, 27, 851; (f) R. W. Saalfrank, B. Hoerner, D. Stalke and J. Salbeck, Angew. Chem. Int. Ed. Eng., 1993, 32, 1179; (g) M. Fujita, D. Oguro, M. Miyazawa, H. Oka, K. Yamaguchi and K. Ogura, Nature, 1995, 378, 469.

6. J.-M. Lehn, Science, 1985, 227, 849.

7. (a) G. V. Oshovsky, D. N. Reinhoudt and W. Verboom, Angew. Chem. Int. Ed., 2007, 46, 2366; (b) M. Yoshizawa, J. K. Klosterman and M. Fujita, Angew. Chem. Int. Ed., 2009, 48, 3418; (c) R. Chakrabarty, P. S. Mukherjee and P. J. Stang, Chem. Rev., 2011, 111, 6810; (d) Y. Yamauchi, M. Yoshizawa and M. Fujita, J. Am. Chem. Soc., 2008, 130, 5832.

8. P. Mukhopadhyay, A. X. Wu and L. Isaacs, J. Org. Chem., 2004, 69, 6157.

9. J. K. Clegg, J. Cremers, A. J. Hogben, B. Breiner, M. M. J. Smulders, J. D. Thoburn and J. R. Nitschke, Chem. Sci., 2013, 4, 68.

10. (a) A. V. Davis, D. Fiedler, G. Seeber, A. Zahl, R. van Eldik and K. N. Raymond, J. Am. Chem. Soc., 2006, 128, 1324; (b) W. Jiang, D. Ajami and J. Rebek Jr, J. Am. Chem. Soc., 2012, 134, 8070.

11. (a) S. Ma, M. M. J. Smulders, Y. R. Hristova, J. K. Clegg, T. K. Ronson, S. Zarra and J. R. Nitschke, J. Am. Chem. Soc., 2013, 135, 5678; (b) A. Jiménez, R. A. Bilbeisi, T. K. Ronson, S. Zarra, C. Woodhead and J. R. Nitschke, Angew. Chem. Int. Ed., 2014, 53, 4556.

12. P. T. Corbett, J. Leclaire, L. Vial, K. R. West, J.-L. Wietor, J. K. M. Sanders and S. Otto, Chem. Rev., 2006, 106, 3652.

13. (a) M. D. Ward and P. R. Raithby, Chem. Soc. Rev., 2013, 42, 1619; (b) M. M. J. Smulders, I. A. Riddell, C. Browne and J. R. Nitschke, Chem. Soc. Rev., 2013, 42, 1728; (c) T. Nakamura, H. Ube and M. Shionoya, Chem. Lett., 2013, 42, 328.

14. E. M. Todd, J. R. Quinn, T. Park and S. C. Zimmerman, Isr. J. Chem., 2005, 45, 381. 
15. (a) K. Osowska and O. Š. Miljanić, Angew. Chem. Int. Ed., 2011, 50, 8345; (b) M. M. Safont-Sempere, G. Fernandez and F. Wurthner, Chem. Rev., 2011, 111, 5784.

16. A. Wu and L. Isaacs, J. Am. Chem. Soc., 2003, 125, 4831.

17. P. Mukhopadhyay, P. Y. Zavalij and L. Isaacs, J. Am. Chem. Soc., 2006, 128, 14093.

18. M. M. J. Smulders, S. Zarra and J. R. Nitschke, J. Am. Chem. Soc., 2013, 135, 7039.

19. S. Chakrabarti, P. Mukhopadhyay, S. Lin and L. Isaacs, Org. Lett., 2007, 9, 2349.

20. P. Mal, D. Schultz, K. Beyeh, K. Rissanen and J. R. Nitschke, Angew. Chem. Int. Ed., 2008, 47, 8297.

21. H. Y. Gan and B. C. Gibb, Chem. Commun., 2012, 48, 1656.

22. S. Ghosh, P. Mukhopadhyay and L. Isaacs, Journal of Systems Chemistry, 2010, 1, 6 .

23. M. E. Belowich and J. F. Stoddart, Chem. Soc. Rev., 2012, 41, 2003.

24. S. Hiraoka, T. Yi, M. Shiro and M. Shionoya, J. Am. Chem. Soc., 2002, 124, 14510.

25. S. Hiraoka, K. Harano, M. Shiro and M. Shionoya, Angew. Chem. Int. Ed., 2005, 44, 2727.

26. N. Kishi, M. Akita and M. Yoshizawa, Angew. Chem. Int. Ed., 2014, 53, 3604.

27. I. A. Riddell, M. M. J. Smulders, J. K. Clegg, Y. R. Hristova, B. Breiner, J. D. Thoburn and J. R. Nitschke, Nat. Chem., 2012, 4, 751.

28. (a) T. Nakamura, H. Ube, M. Shiro and M. Shionoya, Angew. Chem. Int. Ed., 2013, 52, 720; (b) T. Nakamura, H. Ube and M. Shionoya, Angew. Chem. Int. Ed., 2013, 52, 12096.

29. T. Nakamura, H. Ube, R. Miyake and M. Shionoya, J. Am. Chem. Soc., 2013, 135, 18790.

30. A. R. Stefankiewicz, M. R. Sambrook and J. K. M. Sanders, Chem. Sci., 2012, 3, 2326.

31. R. Sekiya, M. Fukuda and R. Kuroda, J. Am. Chem. Soc., 2012, 134, 10987.

32. R. Sekiya and R. Kuroda, Chem. Commun., 2011, 47, 12346.

33. S. Freye, J. Hey, A. Torras-Galán, D. Stalke, R. Herbst-Irmer, M. John and G. H. Clever, Angew. Chem. Int. Ed., 2012, 51, 2191.

34. M. Han, D. M. Engelhard and G. H. Clever, Chem. Soc. Rev., 2014, 43, 1848.

35. J. Rebek Jr, Acc. Chem. Res., 2009, 42, 1660.

36. (a) R. Breslow and L. E. Overman, J. Am. Chem. Soc., 1970, 92, 1075; (b) E. Anslyn and R. Breslow, J. Am. Chem. Soc., 1989, 111, 8931; (c) R. Breslow, J. B. Doherty, G. Guillot and C. Lipsey, J. Am. Chem. Soc., 1978, 100, 3227; (d) I. Tabushi, Acc. Chem. Res., 1982, 15, 66; (e) I. Tabushi, N. Shimizu, T. Sugimoto, M. Shiozuka and K. Yamamura, J. Am. Chem. Soc., 1977, 99, 7100; (f) L. Marinescu and M. Bols, Trends in Glycoscience and Glycotechnology, 2009, 21, 309; (g) J. Bjerre, C. Rousseau, L. Marinescu and M. Bols, Appl. Microbiol. Biotechnol., 2008, 81, 1; (h) I. Tabushi, Tetrahedron, 1984, 40, 269.

37. (a) M. Raynal, P. Ballester, A. Vidal-Ferran and P. W. N. M. van Leeuwen, Chem. Soc. Rev., 2014, 43, 1734; (b) C. J. Hastings, M. D. Pluth, R. G. Bergman and K. N. Raymond, J. Am. Chem. Soc., 2010, 132, 6938 .

38. (a) D. Fiedler, H. van Halbeek, R. G. Bergman and K. N. Raymond, J. Am. Chem. Soc., 2006, 128, 10240; (b) T. S. Koblenz, J.
Wassenaar and J. N. H. Reek, Chem. Soc. Rev., 2008, 37, 247; (c) D. Ajami and J. Rebek Jr, Acc. Chem. Res., 2013, 46, 990.

39. (a) T. Murase, Y. Nishijima and M. Fujita, Chem. Asian J., 2012, 7, 826; (b) Y. Kohyama, T. Murase and M. Fujita, Chem. Commun., 2012, 48, 7811; (c) M. Yoshizawa, M. Tamura and M. Fujita, Science, 2006, 312, 251; (d) A. Cavarzan, A. Scarso, P. Sgarbossa, G. Strukul and J. N. H. Reek, J. Am. Chem. Soc., 2011, 133, 2848; (e) M. Otte, P. F. Kuijpers, O. Troeppner, I. Ivanović-Burmazović, J. N. H. Reek and B. de Bruin, Chem. Eur. J., 2014, 20, 4880.

40. (a) M. Otte, P. F. Kuijpers, O. Troeppner, I. Ivanović-Burmazović, J. N. H. Reek and B. de Bruin, Chem. Eur. J., 2013, 19, 10170; (b) D. Fiedler, R. G. Bergman and K. N. Raymond, Angew. Chem. Int. Ed., 2006, 45, 745; (c) D. Fiedler, D. H. Leung, R. G. Bergman and K. N. Raymond, Acc. Chem. Res., 2004, 38, 349.

41. C. J. Brown, R. G. Bergman and K. N. Raymond, J. Am. Chem. Soc., 2009, 131, 17530.

42. D. M. Vriezema, M. Comellas Aragonès, J. A. A. W. Elemans, J. J. L. M. Cornelissen, A. E. Rowan and R. J. M. Nolte, Chem. Rev., 2005, 105, 1445.

43. (a) B. Breiner, J. K. Clegg and J. R. Nitschke, Chem. Sci., 2011, 2, 51; additional recent examples of the use of molecular containers as "molecular flasks" are: (b) W. M. Hart-Cooper, K. N. Clary, F. D. Toste, R. G. Bergman and K. N. Raymond, J. Am. Chem. Soc., 2012, 134, 17873; (c) Q. Zhang and K. Tiefenbacher, J. Am. Chem. Soc., 2013, 135, 16213; (d) C. J. Brown, G. M. Miller, M. W. Johnson, R. G. Bergman and Kenneth N. Raymond, J. Am. Chem. Soc., 2011, 133, 11964; (e) B. Chatelet, L. Joucla, J.-P. Dutasta, A. Martinez and V. Dufaud, Chem. Eur. J., 2014, DOI: 10.1002/chem.201402058; (f) A. Müller and P. Gouzerh, Chem. Eur. J., 2014, 20, 4862; (g) Y. Jiao, J. Wang, P. Wu, L. Zhao, C. He, J. Zhang and C. Duan, Chem. Eur. $J ., 2014,20,2224$; (h) X. Wu, C. He, X. Wu, S. Qu and C. Duan, Chem. Commun., 2011,47, 8415; (i) S. Horiuchi, T. Murase and M. Fujita, Chem. Asian J., 2011, 6, 1839; (j) M. Hatano, T. Mizuno, A. Izumiseki, R. Usami, T. Asai, M. Akakura and K. Ishihara, Angew. Chem. Int. Ed., 2011, 50, 12189; (k) M. Hatano and K. Ishihara,Chem. Commun., 2012,48, 4273; (1) C. Blaszkiewicz, H. Bricout, E. Léonard, C. Len, D. Landy, C. Cézard, F. Djedaïni-Pilard, E. Monflier and S. Tilloy, Chem. Commun., 2013,49, 6989-6991; (m) L. Adriaenssens, A. Escribano-Cuesta, A. Homs, A. M. Echavarren and Pablo Ballester, Eur. J. Org. Chem., 2013, 2013, 1494.

44. (a) R. C. Wende and P. R. Schreiner, Green Chem., 2012, 14, 1821; (b) J. Zhou, Chem. Asian J., 2010, 5, 422.

45. H. Wei and E. Wang, Chem. Soc. Rev., 2013, 42, 6060.

46. P. Mal, B. Breiner, K. Rissanen and J. R. Nitschke, Science, 2009, 324, 1697.

47. M. M. J. Smulders and J. R. Nitschke, Chem. Sci., 2012, 3, 785.

48. K. K. Coti, M. E. Belowich, M. Liong, M. W. Ambrogio, Y. A. Lau, H. A. Khatib, J. I. Zink, N. M. Khashab and J. F. Stoddart, Nanoscale, 2009, 1, 16.

49. (a) S. Angelos, Y.-W. Yang, K. Patel, J. F. Stoddart and J. I. Zink, Angew. Chem. Int. Ed., 2008, 47, 2222; (b) C. R. Thomas, D. P. Ferris, J.-H. Lee, E. Choi, M. H. Cho, E. S. Kim, J. F. Stoddart, J.-S. Shin, J. Cheon and J. I. Zink, J. Am. Chem. Soc., 2010, 132, 10623; (c) S. Angelos, Y.-W. Yang, N. M. Khashab, J. F. Stoddart and J. I. Zink, J. Am. Chem. Soc., 2009, 131, 11344. 
50. C. Kim, S. S. Agasti, Z. Zhu, L. Isaacs and V. M. Rotello, Nat. Chem., 2010, 2, 962.

51. S. Ghosh and L. Isaacs, J. Am. Chem. Soc., 2010, 132, 4445.

52. Z. Du and Z. Shao, Chem. Soc. Rev., 2013, 42, 1337.

53. M. L. Merlau, M. del Pilar Mejia, S. T. Nguyen and J. T. Hupp, Angew. Chem. Int. Ed., 2001, 40, 4239.

54. Z. J. Wang, C. J. Brown, R. G. Bergman, K. N. Raymond and F. D. Toste, J. Am. Chem. Soc., 2011, 133, 7358.

55. Z. J. Wang, K. N. Clary, R. G. Bergman, K. N. Raymond and F. D. Toste, Nat. Chem., 2013, 5, 100.

56. A. G. Salles Jr, S. Zarra, R. M. Turner and J. R. Nitschke, J. Am. Chem. Soc., 2013, 135, 19143.

57. (a) M. J. Wiester, P. A. Ulmann and C. A. Mirkin, Angew. Chem. Int. Ed., 2011, 50, 114; (b) L. Kovbasyuk and R. Krämer, Chem. Rev., 2004, 104, 3161.

58. (a) S. Le Gac, J.-F. Picron, O. Reinaud and I. Jabin, Org. Biomol. Chem., 2011, 9, 2387; (b) W. J. Ramsay and J. R. Nitschke, J. Am Chem. Soc., 2014, 136, 7038. 